\title{
EFFECT OF AN IN-OFFICE BLEACHING AGENT CONTAINING TWO DIFFERENT CONCENTRATIONS OF TITANIUM DIOXIDE NANO PARTICLES ON THE COLOR AND SURFACE ROUGHNESS OF ENAMEL
}

\author{
H. Hamza*, Haidy N.Salem ${ }^{* *}$, Shahinaz N. Hassan ${ }^{* *}$ and Osama Mosallam**
}

\begin{abstract}
Background: The aim of this study was to evaluate the effect of two different concentrations of titanium dioxide nano particles $\mathrm{TiO}_{2} \mathrm{NP}$ on the color and surface roughness of enamel surface.

Material and methods: 20 bovine anterior teeth were selected. Each tooth was divided into two equal halves and distributed to two groups A and B. Group A: one half is subjected to bleaching agent (AI) and the other half to bleaching agent mixed with $5 \% \mathrm{TiO}_{2} \mathrm{NP}$ (AII). Group B: one half is subjected to bleaching agent $(\mathrm{BI})$ and the other half to bleaching agent mixed with $10 \% \mathrm{TiO}_{2} \mathrm{NP}$ (BII). Surface roughness (Ra) and color changes were evaluated using stereomicroscope and spectrophotometer.
\end{abstract}

Results: There was no statistically significant difference in the roughness Ra between all bleaching groups at $(\mathrm{p}=5981>0.05) .10 \%$ concentration of $\mathrm{TiO}_{2} \mathrm{NP}$ group represented the lowest mean color value while there was no statistically significant difference in bleaching only groups and $5 \%$ concentration $\mathrm{TiO}_{2} \mathrm{NP}$ group using Pair-wise Tukey post-hoc $(\mathrm{p}>0.05)$.

Conclusions: Titanium oxide nano particles had an influence on the efficiency of bleaching agent without jeopardizing enamel surface roughness.

KEYWORDS: Nanoparticles, bleaching, Titanium oxide, spectrophotometer.

\section{INTRODUCTION}

The aesthetic issues associated with teeth discoloration could cause reluctance within the interpersonal relationships as well as a lack of confidence. Therefore, teeth whitening had become a popular service for improving teeth aesthetics ${ }^{(1)}$.
Teeth whitening is a highly desirable esthetic treatment, since it is considered safe and can lead to satisfactory results regarding changing teeth color $^{(2)}$. Hydrogen peroxide is considered the main component among mostly used bleaching agents.

* Professor of Conservative Dentistry. Faculty of Oral and Dental Medicine. Cairo university

** Researcher in Restorative and Dental Materials Department, Oral and Dental Research Division, National Research Centre, Egypt 
The mechanism of bleaching is based upon the release of the reactive forms of oxygen, due to the contact between the peroxide and the tooth surface (3). The oxygen reactive forms of low weight molecules permeate through the tooth structure through the inter-prismatic spaces where they act on and break long chain complex molecules into smaller chain ones causing a reduction in the rate of light absorption by the tooth structure with consequently teeth bleaching ${ }^{(4)}$.

Basically, there are two available bleaching techniques: At-home bleaching that requires using lower concentrations of bleaching agents, and in-office bleaching that employs using higher bleaching agent concentrations.

However, teeth bleaching is considered to be conservative and non-destructive method, several authors have reported its adverse effects on the teeth surface following its application, regarding loss of the organic components from the bleached enamel surface causing its degradation. This might facilitate the recurrence of the teeth discolorations (1). It is known that the contact with some dietary factors like coffee and tea could cause significant teeth staining when there are defects or pores within the teeth surface ${ }^{(5)}$.

Several studies claimed that exposure of enamel to bleaching agents could generate micro-structural changes in the enamel surface ${ }^{(6)}$, as well as changes in the roughness of enamel surface ${ }^{(7)}$.

Recently, nanotechnology has been employed in dentistry to provide materials with improved mechanical properties ${ }^{(\mathbf{8})}$ in order to minimize these adverse effects.

Titanium oxide that is used in cosmetics, paints and white pigments has been introduced to be applied to the tooth whitening. Titanium oxide is less expensive since it is abundant in nature and it is safe for the human body because it is chemically stable ${ }^{(9)}$.

Thus, the aim of the current study was to study the effect of two different concentrations of titanium oxide nano particles on the color and surface roughness of bleached enamel.

\section{MATERIALS AND METHODS}

\section{I-Materials}

\section{1- White Smile bleaching agent:}

It is an in-office chemically-activated bleaching agent composed of hydrogen peroxide HP bleaching gel with a concentration $40 \%$ which upon mixing reaches $32 \%$ concentration. The mixed gel is yellow in color. (Discuss Dental, Germany, 13138).

\section{2- Titanium dioxide Nano particles $\mathrm{TiO}_{2} \mathrm{NP}$ :}

Titanium dioxide Nano particles $\mathrm{TiO}_{2} \mathrm{NP}$ are commercially available in the markets. It is supplied in the form of a powder $(32 \mathrm{~nm})$ to be mixed with distilled water to obtain an appropriate mix to be applied to the teeth (Alfa Aesar PIOB008).

\section{II- Methods}

\section{Teeth selection and preparation}

A total of 20 bovine anterior teeth were selected to be used in the current study. Specimens were divided into two main equal groups $(\mathrm{N}=10)$. Group A: Specimens were subjected to White Smile bleaching agent treatment and bleaching agent mixed with $5 \% \quad \mathrm{TiO}_{2} \mathrm{NP}$ concentration. Group B: Specimens received white smile bleaching gel and white smile bleaching gel mixed with $10 \% \mathrm{TiO}_{2} \mathrm{NP}$ concentration.

Teeth were washed using a brush under running water to be cleaned from any debris. Then, they were cleaned ultrasonically to be free from any extrinsic stains or deposits. Each tooth was cut longitudinally to provide two equal halves using double sided cutting disc at low speed. In Group A one half received bleaching agent application (A1). While, the other half of the same tooth received bleaching agent application mixed with $5 \% \mathrm{TiO}_{2} \mathrm{NP}$ concentration (AII). On the other hand, in Group B one half received bleaching gel application as in group A (BI), while, the other half of the same specimen in the same group received bleaching gel application mixed with $10 \% \mathrm{TiO}_{2} \mathrm{NP}$ concentration (BII). 
The roots of the specimens were cut $2 \mathrm{~mm}$ below the cemento-enamel junction using double side-cutting disc at a low speed. Pulp tissues were removed using barbed broaches ${ }^{(10)}$. Specimens were mounted vertically in a plastic compound jaws for facilitation of the bleaching agent applications.

\section{Bleaching agent application}

\section{Group A :}

One half of the specimens received White Smile chemically-activated bleaching agent (AI) treatment by applying the gel directly $2 \mathrm{~mm}$ to the labial surfaces of the specimens. Then, the gel was removed using suction without rinsing to be ready for another fresh mix. This procedure was repeated three times and in each time the gel was left 15 minutes resulting in a total of 45 minutes application of the bleaching gel ${ }^{(11)}$. The other halves of the same specimens (AII), a $5 \% \mathrm{TiO}_{2} \mathrm{NP}$ concentration was prepared to be mixed with the bleaching gel to be applied the labial surfaces of the specimens. A $0.25 \mathrm{mg}$ of the powder was measured using digital balance ADAM equipment (AE ADAM ${ }^{\mathrm{R}}$ ) and mixed with $10 \mathrm{ml}$ of distilled water using a spatula obtaining a mix in a suspension form. The obtained mixture was then mixed with an amount about 1.5$2 \mathrm{~mm}$ of the bleaching gel and applied to the labial surfaces of the specimens using a brush and left for 15 minutes. This procedure was repeated three times.

\section{Group B:}

One half of the specimens received White Smile bleaching agent treatment (BI) as in Group A. A $10 \%$ concentration of $\mathrm{TiO}_{2} \mathrm{NP}$ was prepared to be mixed with the bleaching gel prior to application. $0.5 \mathrm{mg}$ of Titanium Oxide powder was measured and mixed with $10 \mathrm{ml}$ of distilled water to obtain a suspension mix which was then mixed with $2 \mathrm{~mm}$ of the bleaching gel. The obtained mix was then applied to the labial surfaces of the specimens (BII) as in Group A.
Specimens in both groups were stored in artificial saliva in tightly sealed containers following all treatments to simulate the oral environment until tests were carried out. Specimens were assessed for both surface roughness and color measurement prior to receiving treatments (Baseline receiving no treatments), following Bleaching treatments alone (groups $\mathrm{AI}$ and $\mathrm{BI}$ ) and following bleaching treatments mixed with both concentrations of $\mathrm{TiO}_{2} \mathrm{NP}$ (5\% and 10\%) (groups AII and BII, respectively).

\section{Surface roughness assessment}

Specimens were subjected to surface roughness changes using Digital Camera mounted on a Stereomicroscope (C 5060, Olympus, Japan). It was connected to a Computer Software (BX 60, Olympus, Japan). An arithmetic mean of the depressions and elevations were calculated according to the light reflection for analysis.

\section{Color measurement}

The color values $\left(L^{*}, a^{*}, b^{*}\right)$ for each specimen was measured using Reflective Spectrophotometer (X-Rite, model RM200QC, Neu-Isenburg, Germany ${ }^{(11)}$. Specimens were placed at the center of the measuring head with the aid of a white Teflon holder. That attachment was used to provide repetitive measurements per each specimen upon the same region as well as to prevent the entrance of any external light to the system. The aperture size was set to $4 \mathrm{~mm}$ and the specimens were aligned with the device. A white background was selected and measurements were taken according to the CIE L*a*b* color space relative to the CIE standard illuminant D65. The CIE L*a*b* system was in an approximately uniform color space with coordinates for lightness, namely White-black $\left(\mathrm{L}^{*}\right)$, redness-green $\left(\mathrm{a}^{*}\right)$, and yellowness-blueness $\left(b^{*}\right)$. Measurements were done three times per each specimen and the mean values of $\mathrm{L}^{*} \mathrm{a},{ }^{*} \mathrm{~b}^{*}$ were calculated. The calculation of the color variation $\Delta \mathrm{E}^{*}$ in 3-dimensional $\mathrm{L}^{*} \mathrm{a}^{*} \mathrm{~b}^{*}$ color space was as follows:

$$
\Delta \mathrm{E}_{\mathrm{CIELAB}}=\left(\Delta \mathrm{L}^{* 2}+\Delta \mathrm{a}^{* 2}+\Delta \mathrm{b}^{* 2}\right)^{1 / 2}
$$

Where: $\mathrm{L}=*$ Lightness $(0-100), a=*$ change the 
color of the axis (red/green) and $\mathrm{b}=*$ color variation axis (yellow/blue).

\section{Statistical analysis}

Data analysis was performed in several steps. Multi-factorial ANOVA followed by pair-wise Tukeys post-hoc tests to detect significant effect of the variables (baseline, bleaching and bleaching with titanium oxide concentration). Correlation between color and roughness changes were detected by pearson correlation using Graph-pad Insat statistics software for windows (www.grapgpad.com). $P$ values $\leq 0.05$ are statistically significant in all tests.

\section{RESULTS}

\section{Surface roughness:}

Roughness change $(\mathrm{Ra})$ results (Mean $\pm \mathrm{SD}$ ) for Baseline group as well as groups (A and B) were presented using three-way ANOVA in Table (1). It was found that groups bleaching agent HP only (AI and $\mathrm{BI})$ presented the highest roughness mean $(0.254143 \pm 0.003)$ and $(0.255127 \pm 0.006)$, respectively, followed by group HP agent with $10 \%$ $\mathrm{TiO}_{2}$ NP BII (0.25441) while, group HP agent with 5 $\% \mathrm{TiO}_{2} \mathrm{NP}$ AII presented the lowest roughness mean $(0.252793)$. There was no statistically significant difference between all groups at $(\mathrm{p}=5981>0.05)$. There was no statistically significant difference in the roughness mean between the baseline group and the treatment groups (AI, AII, BI and BII) at $(\mathrm{p}=3333>0.05)$.

\section{Color change}

Color change $(\Delta \mathrm{E})$ results (Mean $\pm \mathrm{SD}$ ) for groups $\mathrm{A}$ and $\mathrm{B}$ were presented using two-way ANOVA test in Table (2). There was no statistically significant difference in the mean color value for AII, AI and BI groups using Pair-wise Tukey posthoc $(\mathrm{p}>0.05)$. While, group BII represented the lowest mean color value.

TABLE (1): Roughness change (Ra) results (Mean $\pm \mathrm{SD}$ ) for Baseline group and bleaching groups

\begin{tabular}{|c|c|c|c|c|}
\hline \multirow[b]{3}{*}{ Variable } & \multicolumn{4}{|c|}{ Groups } \\
\hline & \multicolumn{2}{|c|}{$\mathbf{A}$} & \multicolumn{2}{|c|}{ B } \\
\hline & $\begin{array}{c}\text { Bleaching } \\
\text { agent HP } \\
\text { AI }\end{array}$ & $\begin{array}{c}\text { HP agent with } \\
5 \% \mathrm{TiO}_{2} \mathrm{NP} \\
\text { AII }\end{array}$ & $\begin{array}{c}\text { Bleaching } \\
\text { agent HP } \\
\text { BI }\end{array}$ & $\begin{array}{c}\text { HP agent with } \\
10 \% \mathrm{TiO}_{2} \mathrm{NP} \\
\text { BII }\end{array}$ \\
\hline Baseline & $0.25248 \pm 0.002$ & $0.252113 \pm 0.0019$ & $0.252567 \pm 0.003$ & $0.253523 \pm 0.004$ \\
\hline Bleaching Treatment & $0.254143 \pm 0.003$ & $0.252793 \pm 0.005$ & $0.255127 \pm 0.006$ & $0.25441 \pm 0.0024$ \\
\hline
\end{tabular}

TABLE (2): Color change $(\Delta \mathrm{E})$ results (Mean $\pm \mathrm{SD})$ for bleaching groups:

\begin{tabular}{|c|c|c|c|c|c|c|c|c|}
\hline \multirow[b]{3}{*}{ Subgroup } & \multicolumn{8}{|c|}{ Treatment groups } \\
\hline & \multicolumn{4}{|c|}{$\mathbf{A}$} & \multicolumn{4}{|c|}{ B } \\
\hline & $\mathbf{L}$ & $\mathbf{a}$ & b & $\Delta \mathrm{E}$ & $\mathbf{L}$ & $\mathbf{a}$ & b & $\Delta \mathrm{E}$ \\
\hline I Bleaching agent HP & $2.68 \pm 2.1$ & $1.5 \pm 0.55$ & $-1.46 \pm 0.7$ & $6.27 \pm 2.9$ & $2.87 \pm 2.2$ & $1.19 \pm 0.4$ & $-1.3 \pm 0.7$ & $5.47 \pm 1.9$ \\
\hline II Bleaching with $\mathrm{TiO}_{2} \mathrm{NP}$ ) & $6.49 \pm 2.8$ & $1.22 \pm 0.39$ & $-0.34 \pm 0.4$ & $6.76 \pm 2.0$ & $0.9 \pm 0.5$ & $1.46 \pm 0.5$ & $-1.6 \pm 0.6$ & $2.66 \pm 0.89$ \\
\hline
\end{tabular}




\section{DISCUSSION}

Tooth bleaching is a known method for treating the tooth discoloration. It includes application of a bleaching agent to the tooth surface so as to attain a whitening effect. This procedure depends upon the active agent such as hydrogen peroxide HP. These molecules are responsible for the attack of dark stained molecules and rupture them into less stained molecules ${ }^{(12)}$. The weakening effect of the bleaching agent on sound enamel structure is a major apprehension. Several researches have assessed the consequences of using hydrogen peroxide bleaching agents on the enamel structure. Some stated no or few surface changes to the surface enamel after its procedure, however others reported increased demineralization of enamel surface. The outcomes again have mixed from no influence to noteworthy reduction in hardness of enamel ${ }^{(11-14)}$.

Addition of titanium dioxide Nano particles $\mathrm{TiO}_{2} \mathrm{NP}$ as a catalyst to the bleaching agent is a matter of current exploration to find a safer method with less side effects on dental tissues ${ }^{(13),(14)}$.

Titanium dioxide $\mathrm{TiO}_{2}$ is scheduled as a harmless colorant, with non-recognized unfavorable outcomes. It is an environmental mineral that can be grounded and used as fine particles. It was found that Propolis toothpastes contains $\mathrm{TiO}_{2}$, to aid in whitening the paste since Propolis is brown by nature ${ }^{(14)}$.

In many former studies $\mathrm{TiO}_{2}$ was used as catalyst in the oxidative reaction-because it is considered as a strong reducible agent. Adsorption of $\mathrm{O}_{2}$ will go through a peroxide formation, that can explain the higher catalytic activity of $\mathrm{TiO}_{2}{ }^{(15)}$.

The present study provided data about changes in the roughness and color of the surface enamel resulting from bleaching agent application only, and bleaching agent application mixed with two different concentrations of $\mathrm{TiO}_{2} \mathrm{NP}(5 \%$ and $10 \%)$. Bovine anterior incisor teeth were selected to be used in this study because they are highly available in large quantities, and they have large flat surfaces. ${ }^{(16), 17)}$
Surface roughness measurements were performed for all specimens using Image Analysis software. Analysis were automatically calculated in terms of Ra. ${ }^{(7)}$. Spectrophotometer was used for evaluating the color changes of the enamel surface in all specimens.

At all levels of the study there was an increase in surface roughness values with no significant difference between tested groups for mean roughness data as well as the percentage of change after bleaching at $\mathrm{p}=5981>0.05$ and $(\mathrm{p}=3333>0.05)$ respectively.

These results were in accordance with previous studies ${ }^{(18-20)}$. They concluded that using bleaching gels with higher peroxide concentrations might cause surface alterations to the superficial enamel affecting its roughness. Moreover; Abouassi et al ${ }^{(21)}$ conducted a study claiming that bleaching treatments are minimally invasive procedures but, might cause slight increase in the roughness of the enamel surface. Moreover, several studies ${ }^{(22.23)}$ have revealed the adverse effects of bleaching agents on enamel structure. The adverse effects include dissolutions and increased surface roughness like the initial caries. The greater concentrations responsible for greater effects on the oxidation process and subsequently on the color change; nevertheless, they also end in more adverse effects.

Color changes $(\Delta \mathrm{E})$ results showed no statistically significant difference in the mean color value for $\mathrm{AII}, \mathrm{AI}$ and $\mathrm{BI}$. For $5 \% \mathrm{TiO}_{2} \mathrm{NP}$ group $\mathrm{AII}$; the color changes $(\Delta \mathrm{E}=6.76 \pm 2.0)$ after bleaching was higher compared to the control groups.

This was in an agreement with Bortolatto et al. (24) They stated that bleaching with HP bleaching gel containing titanium oxide nano particles are highly efficient in comparison to the traditional bleaching gel. Cuppini M1 ${ }^{(25)}$ attributed these results to that incorporation of titanium oxide nano particles within hydrogen peroxide gel allows reduction in the required concentration of the latter and increases the safety of the bleaching procedure. Similarly, 
this finding was confirmed in previous study that used modified $\mathrm{TiO}_{2} \mathrm{NP}$ with polydopamine $\left(\mathrm{TiO}_{2} \mathrm{NP}\right.$ /PDA). They found that the whitening results were like that obtained with hydrogen peroxide agents. They concluded that $\mathrm{TiO}_{2} \mathrm{NP}$ based bleaching agents had a similar whitening effect as hydrogen peroxide but also exhibited less harm on enamel structure ${ }^{(26)}$.

These results agreed well with Martin et $\mathrm{al}^{(27)}$ who showed that bleaching agents with less concentration of hydrogen peroxide and containing $\mathrm{TiO}_{2}$ has comparable or further effectual than traditional hydrogen peroxide concentrations $35 \%$, beside the benefit of less threat on the tooth hypersensitivity.

It was stated that there was a strong positive correlation between the titanium concentration in enamel, size of apatite crystal, lightness and enamel hardness. The radius of titanium ${ }^{4+}(0.68 \AA)$ is smaller compared to $\mathrm{Ca}^{2+}(0.99 \AA)$ radius. The $\mathrm{Ca}$ will be replaced by low concentrations of titanium in synthetic HA results in decreased diameter of the cell lattice and the crystal size. It was reported that the titanium concentration in enamel HA was associated with less enamel crystal size ${ }^{(27)}$, which is also in agreement with the previous studies on synthetic HA ${ }^{(28,29)}$.

Ghadimi E et al ${ }^{(30)}$ also confirmed our results. They revealed that the optical properties of tooth enamel were affected by its crystal size; once the size of enamel crystal is larger, its lightness is lesser. This fact is due to that small crystals of tooth enamel will scatter more light. It was concluded that the presence of titanium in tooth enamel structure was associated with both smaller crystal size and higher lightness.

It was found that high concentrations of titanium have a high acidity that might harm tooth surface as well as affect bleaching process. Experimentally, high $\mathrm{pH}$ values ( $\mathrm{pH} 10.0$ ) had a positive effect. This could be explained by that the oxidation of hydroxide ions, which are available on the $\mathrm{TiO}$ NP surface, generates the hydroxyl radicals more easily in alkaline condition. This will result in boost of the degra- dation procedure ${ }^{(14)}$. Ibrahim FAI $2017^{(16)}$ suggested that the acidity may be a key cause for the adverse effects of HP with lower $\mathrm{pH}$ value. They stated that increasing the concentration of $\mathrm{TiO}_{2} \mathrm{NP}$ has no significant effect on the catalytic procedure which denotes that when the degradation procedure occurs at an alkaline medium, less $\mathrm{TiO}_{2} \mathrm{NP}$ concentration will be needed for enhanced degradation efficiency.

Adding irreversible electron acceptor to the reaction confines the efficacy of $\mathrm{TiO}_{2} \mathrm{NP}$ as catalyst; electron-hole recombination. This causes energy wasting step that restricts reaching to the quantum yield ${ }^{(16)}$.

Above mentioned, there is a relation between micro hardness of tooth enamel and the size of the carbonate apatite CAP crystals. It is well recognized that hardness of the material is significantly increased by decreasing the crystals size. This would clarify the negative effect of increasing the concentration of $\mathrm{TiO} 2$ since the bleaching mechanism depends on both penetration ability of the bleaching gel as well as the permeability of enamel surface ${ }^{(30)}$.

Based on our study, it has been suggested that peroxide-based materials might contribute to the whitening effect. Moreover, the effect of incorporation of $\mathrm{TiO}_{2}$ nanoparticles to dental bleaching is concentration dependent. The clinical relevance and significance of these concentration alterations remain to be investigated in further detail.

\section{CONCLUSION}

Under the restraints of this study. Incorporation of $\mathrm{TiO}_{2}$ nanoparticles with $5 \mathrm{wt} \%$ concentrations into the in-office chemically-activated bleaching agent showed a comparable effect on the bleaching upon comparison with chemically-activated bleaching agent alone without jeopardizing surface texture. Increasing the concentration of $\mathrm{TiO}_{2}$ nanoparticles to $10 \mathrm{wt} \%$ concentration is not advantageous, nor for the results of the surface roughness, neither to accelerate the peroxides action. 


\section{REFERENCES}

1. Majeed A, Faroog I, Grobler SR and Rossouw RJ: A review of the efficacy and adverse effects of various tooth whitening. J Coll Physicians Surq Pak. 2015;25: 891-896.

2. Borges AB, Zanatta RF, Barros ACSM, Silva LC, Pucci $\mathrm{CR}$ and Torres CRG: Effect of hydrogen peroxide concentration on enamel color and microhardness. Operative Dentistry. 2015; 40: 96-101.

3. Carey CM: Tooth whitening: What we now know. J Evid Based Dent Pract. 2014; 14: 70-76.

4. Shahabi S, Assadian H, Nahavandi AM and Nokhbatolfoghaei H: Comparison of tooth color change after bleaching with conventional and different light activated methods. J Lasers Med Sci. 2018; 9: 27-31.

5. Muhammet K: Efficacy of whitening oral rinses and dentifrices on color stability of bleached teeth. Acta Biomaterialia Odontolgica Scandinavica. 2015;1: 29-34.

6. Palominok P and Tirapelli C: The effect of home-use and in office bleaching treatments combined with experimental desensitizing agents on enamel and dentin. Eur J Dent. 2015; 9: 66-73.

7. Cavalli V, Da Rosa A, Da Silva DP, Kury M, Liporoni PCS, Soares LE and Martins AA: Effects of experimental bleaching agents on the mineral content of sound and demineralized enamels. J App Oral Sci. 2018; 26: 1590-1678.

8. Lima FV, Mendes C, Zanetti-Ramos BG, Nadi JK, Cardoso SG, Bernardon JK and Silva MAS: Carbamide peroxide nano particle for dental whitening application: Characterization, stability and in vivo/in situ evaluation. Colloids Surf B Biointerfaces. 2019; 4: 326-333.

9. Kishi A, Otsuki M, Sadr A, Ikeda M and Tagmi J: Effect of light units on tooth bleaching with visible light activating titanium dioxide photocatalyst. Dent Mate J. 2011; 30: 723-729.

10. Whang HJ and Shin DH: Effects of applying antioxidants on bond strength of bleached bovine dentin. Restorative Dentistry and Endodontics. 2014; 14: 37-43.

11. Alencar MS, Bombonatti JFS, Maenosono RM, soares AF, Wang L and Mondelli RFL: Effect of two antioxidant agents on microtensile bond strength to bleached enamel. Brazilian Dental Journal. 2016; 27: 532-536.

12. Venkatesan SM, Narayan GS, Ramachandran AK and Indira R: The effect of two bleaching agents on the phosphate concentration of enamel evaluated by raman spectroscopy: An ex vivo study. Contemp Clinical Dentistry. 2012; 3; 172-176.

13. Koudriavtsev TV, Sedo RD and Sancho OAR: Titanium dioxde in dental enamel as a trace element and its variation with bleaching. Journal of Clinical Exp Dentistry. 2018; 10: $537-541$.

14. Klarić E, Marcius M, Ristić M, Sever I, Prskalo K, Tarle Z. Surface changes of enamel and dentin after two different bleaching procedures. Acta Clin Croat. 2013 Dec; 52(4):419-29.

15. Alexandrino L, Gomes $\mathrm{Y}$, Alves E, Costi H, Rogez $\mathrm{H}$ and Silva C: Effects of bleaching agent with calcium on bovine enamel. European Journal of Dentistry 2014; 8: 320-325.

16. Ibrahim FAI, AL- Ghobashy MA, Abd EL-Rahman MK and Abo-Elmagd IF: Optimization and in line piotentiometric monitoring of enhanced photocatalytic degradation kinetics of Gemifloxacin using TIO2 nanoparticles/H2o2. Environ Sci Pollut Res. 2017; 24: 23880-23892.

17. Alexandrino L, Gomes Y, Alves E, Costi H, Rogez H and Silva C: Effects of bleaching agent with calcium on bovine enamel. European Journal of Dentistry 2014; 8: 320-325.

18. Eimar H, Ghadimi E, Marelli B, Nazhat SN and Amin WM: Regulation of enamel hardness by its crystallographic dimensions. Acta Biomater. 2012; 8: 34003410.

19. Navimipour EJ, Mohammadi N, Mostafazadeh S, Ghojazadeh $\mathrm{M}$ and Oskoee PA: Effect of delaying tooth brushing during bleaching on enamel surface roughness: An in vitro study. Operative Dentistry. 2013; 38: 218-225.

20. Basting R, Rodrigues AL and Serra MC: Micromorphology and surface roughness of sound and demineralized enamel and dentin bleached with a ten percent carbamide peroxide bleaching agent. American Journal of Dentistry. 2007; 20: 97-102.

21. McGuckin RS1, Babin JF, Meyer BJ. Alterations in human enamel surface morphology following vital bleaching. J Prosthet Dent. 1992 Nov; 68(5): 754-60

22. Abouassi T, Wolkewitz M and Hahn P: Effect of carbamide peroxide and hydrogen peroxide on enamel surface: An in vitro study. Clinical Oral Investigation. 2011; 15: $673-680$.

23. Nematianaraki S, Fekrazad R, Naghibi N, Kalhori KAM and Junior AB: Effects of the bleaching procedures on enamel micro-hardness: Plasma arc and diode laser comparison. Laser. 2015; 24: 173-177. 
24. Bortolatto JF, Pretel H, Floros MC, Luizzi ACC, Dantas AAR, Moncada G and Oliveira OBD: Low concentration H202/Tio-N in office bleaching: A randomized clinical trial. JDR Clinical Research Supplement. 2014; 93: 674-715.

25. Cuppini M1, Leitune VCB1, Souza M1, Alves AK2, Samuel SMW1, Collares FM1. In vitro evaluation of visible light-activated titanium dioxide photocatalysis for in-office dental bleaching. Dent Mater J. 2019 Feb 8;38(1):68-74.

26. Lopes GC, Boniss L, Baratieri LN, Vierra LC and Monteiro JR: Effect of bleaching agents on hardness and morphology of enamel. Journal of Esthetic and Restorative Dentistry. 2002; 14: 24-30.
27. Martin J, Fernandez E, Bahamodes V, Werner A, Elphick $\mathrm{K}$ and Oliveira OB: Dentin hypersensitivity after teeth bleaching with in-office systems: Randomized Clinical Trial. Am J Dent. 2013; 26: 10-14.

28. Ergun C1, Doremus R, Lanford W. Hydroxylapatite and titanium: interfacial reactions. J Biomed Mater Res A. 2003 Jun 1;65(3):336-43.

29. Mcguckin RS, Babine JF and Meyer BJ: Alterations in human enamel surface morphology following vital bleaching. Journal of Prosthetic Dentistry. 1992; 68: 754-760.

30. Ghadimi E, Emimar H, Marelli B, Nazhat SN, Asgharian $\mathrm{M}$ and Vali H: Trace elements can influence the physical properties of tooth enamel. Springer Plus. 2013; 2: 499. 